\title{
Child abuse and the dynamics of silence
}

Warwick Middleton, Pam Stavropoulos, Martin J. Dorahy, Christa Krüger, Roberto Lewis-Fernández, Alfonso Martínez-Taboas, Vedat Sar, Bethany Brand

Pam Stavropoulos, Ph.D.

Head of Research and Clinical Practice, Adults Surviving Child Abuse, Sydney, Australia, pstavropoulos@asca.org.au

Martin Dorahy, Ph.D.

Associate Professor, Department of Psychology, University of Canterbury, New Zealand. martin.dorahy@canterbury.ac.nz

Christa Krüger, M.D.

Professor, Department of Psychiatry, University of Pretoria, South Africa.

christa.kruger@up.ac.za

Roberto Lewis-Fernández, M.D.

Professor, Department of Psychiatry, Columbia University, New York, New York, USA

rlewis@nyspi.columbia.edu

Alfonso Martínez-Taboas, Ph.D.

Associate Professor, Carlos Albizu University, San Juan, Puerto Rico.

AMartínez@albizu.edu

Vedat Sar, M.D.

Professor, Department of Psychiatry, Istanbul Faculty of Medicine, Istanbul University, Turkey.

President, European Society for Traumatic Stress Studies (ESTSS), Vienna, Austria

vsar@istanbul.edu.tr

Bethany Brand, Ph.D.

Professor of Psychology, Towson University, Towson, Maryland, USA,

BBrand@towson.edu

\section{Corresponding Author:}

Adjunct Professor Warwick Middleton

MB BS, FRANZCP, MD., Chair, The Cannan Institute

In constructively responding to our Viewpoint paper on institutional abuse and societal silence, Haliburn (2014) articulates several core challenges for psychiatry. These are that the mental health consequences of early trauma are too compelling to ignore, that societal silence has a strong tendency to be pervasive, and that we thus have to avoid passively opting for silence if we are to be part of the solution rather than an extension of the problem.

It is useful to reflect on the nature of this silence. Its mechanisms are age-old. Generally speaking, the more hierarchical and the more male-dominated societies are, the fewer the rights of women and children, and the less interest there is in holding accountable those who exploit and abuse them. 
From the late nineteenth century onwards, there have been patchy attempts to shine light on outwardly respectable individuals and institutions grievously abusing children and aggressively silencing those who tried to speak an inconvenient truth.

It is cause for reflection that along with other groupings, psychiatry has accommodated society's need to maintain silence. Examples from different time periods include nineteenth century characterization of hysteria as the province of suggestible and mendacious women, extension in the $20^{\text {th }}$ century of diagnostic boundaries of the "schizophrenia" construct to incorporate virtually anyone who heard "voices", and more recently, intermittent attempts to characterize profoundly traumatized dissociative individuals as recipients of an invalid "fad" or iatrogenic diagnosis, having a defective memory, or a personality disorder. In addition, until the 1970s there was no interest nor any serious attempt to investigate the epidemiology and clinical course of women and children with child sexual abuse histories.

Whether it is the controlling incestuous father, the politically connected pedophile ring, or a hierarchical church that actively avoids the reporting of lifedestroying crimes to law enforcement authorities, the mechanisms for ensuring silence are very similar. These are, threat and the manipulation of shame, discrediting the victim's testimony, isolating, rejecting and dispossessing those who try to speak out, the "buying of silence", misuse of legal powers to intimidate, death threats, and in some cases, attempted murder (including pressure to suicide) or even actual murder.

When an individual or an institution sees fit to serially sexually abuse children or to actively cover up this abuse, it is axiomatic that the individual or institution involved cares little about the welfare of such children, despite any public utterances to the contrary. Clearly the children are viewed as expendable. If the abusers and their enablers must choose between career destruction, public disgrace, the reputation and protection of their organisation, legal accountability and jail on the one hand, and validation of victims on the other, it is starkly obvious why perpetrators - irrespective of their social standing and economic status - generally use every means at their disposal to ensure that the veil of silence continues.

The Australian Royal Commission into institutional responses to child sexual abuse thus potentially represents a tipping point for our awareness. This is the first time that a society has comprehensively attempted to expose the networks and processes involved in maintaining silence about child sexual abuse within its various institutions.

In psychiatry, we have not fully grappled with the enormous impact of child abuse on the mental consequences of so many of our patients. Even in these more informed days, history taking may still not explore core child abuse issues. A history of child sexual or physical abuse may be afforded little etiological significance in the patient evaluated for chronic depression, substance dependence, somatoform complaints, "borderline" tendencies or potentially psychotic symptoms. 
Haliburn distinguishes between risk factors and risk markers with respect to childhood adversities. Short of the unthinkable study design in which randomly assigned children are allocated to two groups - one to be abused, the other not, and then followed up into adulthood - the closest any study has come to "proving" that childhood sexual abuse is very damaging to individuals has been the quarter-century longitudinal study by Frank Putnam and Penelope Trickett (Trickett et al., 2011) that followed up sexually abused girls and closely matched controls (with quite extraordinary participant retention rates).

Reporting at the 23-year mark, Trickett et al. concluded that sexually abused females (on average) showed deleterious sequelae across a host of biopsychosocial domains. These include more major illnesses and healthcare utilization, Diagnostic and Statistical Manual of Mental Disorders diagnoses, earlier onsets of puberty, cognitive deficits, depression, persistent posttraumatic stress disorder, dissociative symptoms, drug and alcohol abuse, hypothalamicpituitary-adrenal attenuation, asymmetrical stress responses, high rates of obesity, dropping out of high school, self-mutilation, maladaptive sexual development, teen pregnancies, premature deliveries, physical and sexual revictimization, and domestic violence.

Adding further support to the robust findings of the Adverse Childhood Experience studies (Felitti and Anda, 2010), in an extension of the National Comorbidity Survey, Putnam et al. (2013) confirmed previous findings of steadily increasing risk for negative adult outcomes with increasing types of childhood adversity. Tellingly, of the eight childhood adversities used in the aggregated analysis, sexual abuse proved to be the most potent childhood adversity, especially for women. As the Royal Commission allows society to lift the shroud of silence, psychiatry has its part to play in continuing to recognise, assess, research and promote the deleterious impact of child abuse on adult functioning, and to ensure that silence does not descend upon this issue again.

\section{References}

Felitti VJ and Anda RF (2010) The Relationship of Adverse Childhood Experiences to Adult Medical Disease, Psychiatric Disorders and Sexual Behavior: Implications for Healthcare. Ch. 8 in Lanius RA, Vermetten E and Pain C. The Impact of Early Life Trauma on Health and Disease. Cambridge University Press, pp.77-87.

Haliburn J (2014) Links between child abuse and major mental illness psychiatry's response. Australian and New Zealand Journal of Psychiatry 48:

Putnam KT, Harris WW and Putnam FW (2013) Synergistic childhood adversities and complex adult psychopathology. Journal of Traumatic Stress 26:435-442.

Trickett PK, Noll JG and Putnam FW (2011) The impact of sexual abuse on female development: Lessons from a multigenerational, longitudinal research study. Development and Psychopathology 23:453-476. 